48-55०), sacral slope (SS: normal value: $36-42^{\circ}$ ) and lateral pelvic tilt (LPT: normal value: $\left.12-18^{\circ}\right)$. Spinal stature parameters were thoracic kyphosis (normal value: 41-48 ), lumbar lordosis (normal value: 43-61 ${ }^{\circ}$ ), sagittal vertical axis (SVA: normal value: $<30 \mathrm{~mm}$ ) and spinosacred angle (SSA: normal value: $<132$ )

Results: We enrolled 29 men (58\%) and 21 women (42\%) with an average age of $42.6 \pm 11.09$ years [20 -79]. The mean duration of SA was $12.4 \pm 9.71$ years [2-46]. SA was axial in 17 patients (34\%), and axial and peripheral in 29 patients $(58 \%)$. The median PI was $50.7 \pm 11.81^{\circ}$. The median SS was $35.8 \pm 11.64^{\circ}$. The median LPT was $14.9 \pm 8.97^{\circ}$ The average value of thoracic kyphosis was $52.1 \pm 12.1^{\circ}$. The average value of lumbar lordosis was $37.4 \pm 16$. The median SVA was $25.2 \pm$ $55.88 \mathrm{~mm}$ and the median of SSA was $123.9 \pm 16.64^{\circ}$. Thus, deformity of the thoracic spine was found in 40 patients (80\%) with thoracic hypercyphosis type and thoracic rectitude in $12 \%$ and $68 \%$ of cases respectively. The deformity of the lumbar spine was found in 40 patients $(80 \%)$ with lumbar hyperlordosis type and lumbar rectitude in $74 \%$ and $6 \%$ of cases respectively. From this construction and segmenting the SS values we were able to classify the type of back according to Roussouly : the type 2 back was the most frequently found (40\%), followed by type 3 back $(34 \%)$, type 4 back $(24 \%)$, and type 1 back $(2 \%)$. Spinal deform ities were more frequent in women $(p=0.004)$ and associated with a longer duration of the disease $(p<0.0001)$ and a longer duration before initiation of treatment $(p<0.0001)$ (Table 1).

Conclusion: Our study showed that the EOS system was a useful technique in assessing pelvic and spinal stature in patients with SA

Abstract THU0402 -Table 1. Association of the spinal deformities with clinical parameters

Parameter Spinal deformities

Female sex

Age

Duration of the disease

$\mathrm{p}=0.004$

$\mathrm{p}=0.126$

Active disease

$\mathrm{p}<0.000$

Axial spondyloarthritis

Duration before treatment

$\mathrm{p}=0.233$

$\mathrm{p}=0.146$

$\mathrm{p}<0.0001$

Disclosure of Interests: None declared

DOI: 10.1136/annrheumdis-2019-eular.6196

\section{THU0403 AXIAL SPONDYLOARTHRITIS INDUCES MUSCLE DISFUNCTION, THE ROLE OF BODY COMPOSITION PARAMETERS: MYOSPA STUDY}

Maria Luisa Sequeira ${ }^{1}$, Inês Da Costa Santos ${ }^{1}$, Rita Amador ${ }^{1}$, Lucia Domingues ${ }^{1}$, Carolina Crespo ${ }^{1}$, Santiago Rodrigues-Manica ${ }^{1}$, Sofia Ramiro ${ }^{2}$

Alexandre Sepriano $^{1}$, Diana Teixeira ${ }^{1}$, Agna Neto $^{1,3}$, Rita Pinheiro Torres ${ }^{1,3}$, Conceição Calhau ${ }^{1}$, Jaime Branco ${ }^{1,3}$, Fernando Pimentel Dos Santos ${ }^{1,3} .{ }^{1}$ NOVA University of Lisbon, CEDOC - NOVA Medical School / FCM, Lisboa, Portugal; ${ }^{2}$ Leiden University Medical Center, Rheumatology, Leiden, Netherlands; ${ }^{3} \mathrm{CHLO}$ Hospital de Egas Moniz, Rheumatology Department, Lisboa, Portugal

Background: Sarcopenia as well as abnormalities in body composition are common features in several chronic diseases and have been shown to lead to increased morbidity and mortality. However, their assessment in young patients with axial spondyloarthritis (axSpA) has not been performed thus far.

Objectives: To assess the skeletal muscle mass, strength and performance as well as body composition in patients with axSpA compared to healthy controls.

Methods: Patients between 18 and 50 years of age with the diagnosis of axSpA and short disease duration (under 10 years) and classified according to the ASAS criteria were included. Healthy individuals matched by gender and age (1:1) were used as control group. Muscle strength (MS) was assessed by resisted flexion of the dominant forearm using a hand dynamometer. Muscle performance was assessed with the $60 \mathrm{sec}-$ ond sit-to-stand test (STS60) and with 5 times sit-to-stand test (STS5). Body composition was assessed with octapolar multifrequency bioelectrical impedance analysis (InBody 770). The level of physical activity was measured by the IPAQ questionnaire. BASDAI and BASFI were used to evaluated disease activity and function, respectively. All measures (except age and disease duration) are reported as median and $25^{\text {th }}$ and $75^{\text {th }}$ percentiles. Non-parametric tests were used to compare groups.

Results: A total of 27 patients and 27 controls were included [mean age (36.5 \pm SD 1.0), 66\% males]. AxSpA patients had symptom duration of $7.0 \pm$ SD 0.9 years, BASDAI 2.7 (1.4-3.6) and BASFI 0.9 (0.3-3.2). Compared to controls, axSpA patients had less $\mathrm{MS}$ in the dominant upper limb (DUL) (46.0 (37.5-70.6) vs $71.2(54.1-83.4) \mathrm{kg}, \mathrm{p}=0.006)$ and worse performance on the STS60 test $(48.0$ (27.5-64.3) vs 63.0 (53.0-68.0) repetitions, $\mathrm{p}=0.010)$. These differences were maintained after normalization for lean mass (LM) (MS_DUL/LM_DUL and STS60/Total_LM). In addition, compared to controls, axSpA patients had higher body fat (BF) (19.8 $(12.1-29.1)$ vs $15.7(10.1-22.2) \mathrm{kg}, \mathrm{p}=0.041)$, torso fat (TF) (10.3 (6.3 15.9) vs $8.1(5.1-11.1) \mathrm{kg}, \mathrm{p}=0.450)$ and visceral fat (VF) (87.3 (52.7$145.1)$ vs $\left.65.4(41.8-96.4) \mathrm{cm}^{2}, \mathrm{p}=0.034\right)$. No differences were registered for weight, body mass index, total body water, extracellular water, fat free mass, LM and bone mineral content between groups. The level of physical activity, measured by the IPAQ questionnaire, was identical between patients and healthy controls $(p=0.500)$.

Conclusion: Compared to healthy controls, young axSpA patients have a reduction in muscle strength and muscle performance with maintenance of muscle mass and levels of physical activity. These preliminary results underline the relevance of further investigations.

Abstract THU0403 - Table 1. Subject characteristics

\begin{tabular}{|c|c|c|c|}
\hline Variable & $\begin{array}{l}\text { Patients } \\
\mathrm{N}=27\end{array}$ & $\begin{array}{c}\text { Controls } \\
N=27\end{array}$ & p-value \\
\hline Age (years) & $37(32-43)$ & $36(30-44)$ & 0.808 \\
\hline Gender ( $0^{x} \%$ : 우) & $66.7: 33.3$ & $66.7: 33.3$ & $0.922 \S$ \\
\hline $\begin{array}{l}\text { Symptom duration } \\
\text { (years) }\end{array}$ & $7.0(4.0-10.0)$ & & \\
\hline $\begin{array}{l}\text { IPAQ } \\
\text { (low\% : moderate-high\%) }\end{array}$ & $29.2: 70.8$ & $20.8: 79.2$ & $0.505 \S$ \\
\hline LM $(\mathrm{Kg})$ & $50.1(44.5-57.8)$ & $\begin{array}{c}54.1(43.2- \\
\quad 60.2)\end{array}$ & 0.592 \\
\hline $\mathrm{BF}(\mathrm{Kg})$ & $19.8(12.1-29.1)$ & $\begin{array}{l}15.7(10.1- \\
22.2)\end{array}$ & 0.041 \\
\hline $\operatorname{TF}(\mathrm{Kg})$ & $10.3(6.3-15.9)$ & $8.1(5.1-11.1)$ & 0.045 \\
\hline VF Area $(\mathrm{cm} 2)$ & $\begin{array}{c}87.3(52.7- \\
145.1)\end{array}$ & $\begin{array}{c}65.4(41.8- \\
96.4)\end{array}$ & 0.034 \\
\hline MS_DUL (Kg) & $46.0(37.5-70.6)$ & $\begin{array}{c}71.2(54.1- \\
83.4)\end{array}$ & 0.006 \\
\hline STS60 test (repetitions) & $48.0(27.5-64.3)$ & $\begin{array}{c}63.0(53.0- \\
68.0)\end{array}$ & 0.010 \\
\hline
\end{tabular}

*Values are median (IQR) unless otherwise indicated. Comparison between patients and controls tested by paired samples $t$-test unless otherwise indicated. §Comparison between patients and controls tested by Chi-Square test in Gender and Physical Activity variables.

Disclosure of Interests: Maria Luisa Sequeira: None declared, Inês da Costa Santos: None declared, Rita Amador: None declared, Lucia Dom ingues: None declared, Carolina Crespo: None declared, Santiago Rodrigues-Manica Grant/research support from: Novartis, MSD, Speakers bureau: Novartis, Sofia Ramiro Grant/research support from: MSD, Consultant for: AbbVie, Lilly, MSD, Novartis, Pfizer, Sanofi, Speakers bureau: AbbVie, Lilly, MSD, Novartis, Pfizer, Sanofi, Alexandre Sepriano: None declared, Diana Teixeira: None declared, Agna Neto: None declared, Rita Pinheiro Torres: None declared, Conceição Calhau: None declared, Jaime Branco: None declared, Fernando Pimentel dos Santos Grant/research support from: From Abbvie and Novartis, Speakers bureau: Abbvie, Novartis, Pfizer, Biogen

DOI: 10.1136/annrheumdis-2019-eular.6817

\section{THU0404 DICKKOPF-1 SERUM LEVELS AND THEIR CORRELATION WITH ACTIVE AND CHRONIC MRI- CHANGES OF SACROILIAC JOINTS AND CLINICAL INDICES IN PATIENTS WITH SPONDYLOARTHRITIS}

luliia Shynkaruk ${ }^{1}$, Oleg laremenko ${ }^{1}$, Dmytro Fedkov ${ }^{1}$, Kateryna laremenko ${ }^{2}$. ${ }^{1}$ Bogomolets National Medical University, The Department of Internal Medicine\#3, Kyiv, Ukraine; ${ }^{2}$ Oleksandrivska City Clinical Hospital, The Laboratory Department, Kyiv, Ukraine

Background: The lack of valid biochemical markers for spondyloarthritis (SpA) patients requires searching the additional options to increase sensitivity of clinical and radiological methods in validation of changes in sac roiliac joints $(S \mid J)$. The molecular basis for the link between inflammation and new bone formation in $\mathrm{SpA}$ is still not clear. It has recently been shown that low serum levels of the Dickkopf-1 (Dkk-1), the natural inhibitor of Wnt protein, is associated with the formation of new syndesmophytes in patients with SpA [1]. Dkk-1 may be a main factor in blocking new bone formation [2], and might play a role of potential biomarker in SpA patients. 
Objectives: To determine the serum levels of Dkk-1 and their relationship with active and chronic changes in SIJ on MRI, indices and laboratory parameters of disease activity and functional status in SpA patients. Methods: This study includes 105 SpA patients (89.5\% HLA B27 positive) and 15 healthy age- and gender- matched controls. Dkk-1 serum levels (pmol/l) were conducted by ELISA. Active inflammatory lesions in SIJ were evaluated by Spondyloarthritis Research Consortium of Canada (SPARCC) MRI SIJ score $(0-72, n=69)$ and chronic changes by Danish scoring method (0-48). Bath Ankylosing Spondylitis Disease Activity Index (BASDAI, mm), Bath Ankylosing Spondylitis Functional Index (BASFI, $\mathrm{mm}$ ), C-reactive protein (CRP, $\mathrm{mg} / \mathrm{l})$ and erythrocyte sedimentation rate (ESR, $\mathrm{mm} / \mathrm{hr}$ ) were recorded. Statistical analysis was performed using Spearman correlation coefficient, Student t-test and receiver operating characteristic (ROC) curves

Results: Mean value $(\mathrm{M} \pm \sigma)$ of $D k k-1$ was $45.1 \pm 36.3$. The mean value of indices and laboratory parameters were: BASDAI - 44.5 \pm 19.3 , BASFI $31.1 \pm 23.1$, CRP $-20.6 \pm 31.3$, ESR - 26.8 \pm 22.0 . SPARCC score was

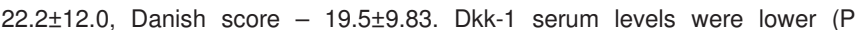
$<0.01$ ) in SpA patients compare with the controls. ROC analysis indicated that the AUC for Dkk-1 is $0.88 \pm 0.05 \quad(p<0.001)$, which indicates strong capacity to differentiate groups of SpA patients with healthy controls (sensitivity - $87 \%$, specificity - $79 \%$ ).

There was significant negative correlation between Dkk-1 with chronic lesions in SIJ by Danish score $(r=-0.250, p=0.046)$. Dkk-1 showed positive correlation with CRP $(r=0.216, p=0.028)$.

There was no significant correlation of serum Dkk-1 levels with SPARCC, BASDAI, BASFI and ESR.

Conclusion: Dkk-1 levels are significantly lower in SpA patients compare with healthy controls and has a strong association with SpA. Dkk-1 significantly negatively correlates with chronic changes in SIJ on MRI, that may confirm that deficiency of Dkk-1 could increase progression of pathological changes in SIJ. Dkk-1 correlates only with CRP level, but none of the other indices and laboratory parameters of disease activity and functional status.

\section{REFERENCES:}

[1] Song I-H. Ann Rheum Dis. 2011; 70: 1257-1263

[2] Zhao Z. Clin Rheumatol. 2018. doi: 10.1007/s10067-018-4284-y.

Disclosure of Interests: Iuliia Shynkaruk: None declared, Oleg laremenko: None declared, Dmytro Fedkov Grant/research support from: MSD, AbbVie, ProPharma, Laboratoires Expanscience; Consultant for: MSD, AbbVie, ProPharma, Laboratoires Expanscience; Speakers bureau: Janssen, Kateryna laremenko: None declared

DOI: 10.1136/annrheumdis-2019-eular.3976

\section{THU0405 PREVALENCE OF FIBROMYALGIA IN INFLAMMATORY BOWEL DISEASE (IBD) PATIENTS: A SINGLE CENTRE OBSERVATIONAL PROSPECTIVE STUDY}

llaria Tinazzi ${ }^{1}$, Angela Variola ${ }^{2}$, Andrea Geccherle $^{2}$, Antonio Marchetta $^{1}$, Dennis Mcgonagle ${ }^{3}$. 'Sacro Cuore Hospital, Unit of Rheumatology, Negrar Verona, Italy; ${ }^{2}$ Sacro Cuore Hospital, IBD Unit, Negrar Verona, Italy, ${ }^{3} 2 \mathrm{NIHR}$ Leeds Musculoskeletal Biomedical Research Unit, Leeds Teaching Hospitals Trust and The University of Leeds, Leeds, United Kingdom

Background: Joint pain is frequently reported by IBD patients and can be associated to extra-intestinal manifestations of diseases or adverse events associated to anti-TNF or vedolizumab therapy and also associated with other non-SpA-disease related factors including mechanical/ degenerative problems. An appropriate rheumatological referral pathway is crucial to drive therapeutic strategy in case of concomitant spondyloarthritis $(\mathrm{SpA})$. Fibromyalgia is a frequent cause of chronic pain that needs to be identified in order to not overestimate the prevalence of $S p A$ in IBD patients

Objectives: The aim of the study was to assess the prevalence of FM in a cohort of IBD outpatients

Methods: Consecutive patients of the IBD Unit coming for a routine visit were screened by a rheumatologist in order to identify cases presenting the 2010 ACR criteria for FM or ASAS criteria for SpA $(1,2)$. Patients affected by other rheumatic conditions such as rheumatoid arthritis and crystal arthritis were excluded from the study. The rheumatological assessment included a 66 swollen joint count (SJC) and 68 TJC, MASEI, $\mathrm{LEI}$ and the fibromyalgia tender points examination. The patient completed BASDAI and BASFI on the day of clinical evaluation. Imaging exams (MSK ultrasound, MRI) and HLA-B27 determination were requested if needed for diagnostic confirmation
Results: Between January to May 2018, 210 patients were enrolled in the study and 181 completed the clinical and imaging/laboratory assessment if requested for diagnostic purpose. examination. A total of 44 patients $(24.3 \%)$ in the IBD cohort met the ACR 2010 criteria for FM. 34 patients $(18.8 \%)$ presented the criteria for primary $\mathrm{FM}$, and 10 patients $(5.5 \%)$ presented $\mathrm{FM}$ and SpA. Of note FM patients presented LEI; BASDAI and BASFI scores higher than SpA patients

Conclusion: FM is a common comorbidity in IBD patients and can be associated to SpA. An appropriate rheumatological referral is crucial exclude a concomitant $\mathrm{SpA}$ and to manage FM

\section{REFERENCES}

[1] Wolfe, et al. The American College of Rheumatology preliminary diagnostic criteria for fibromyalgia and measurement of symptom severity. Arthritis Care and Research. 2010;62(5):600-610.

[2] Rudwaleit M, et al. The Assessment of SpondyloArthritis international Society classification criteria for peripheral spondyloarthritis and for spondyloarthritis in general. Ann Rheum Dis 2011;70:25-31

Disclosure of Interests: Ilaria Tinazzi: None declared, Angela Variola: None declared, Andrea Geccherle: None declared, Antonio Marchetta: None declared, Dennis McGonagle Consultant for: Lilly, Novartis UCB, Speakers bureau: Lilly, Novartis UCB

DOI: 10.1136/annrheumdis-2019-eular.5847

\section{THU0406 ULTRASONOGRAPHIC INVOLVEMENT OF THE ANTERIOR CHEST WALL IN SPONDYLOARTHRITIS, A FIVE YEARS FOLLOW UP STUDY}

Frank Verhoeven $^{1,2}$, Maxime Sondag ${ }^{1}$, Mickael Chouk ${ }^{1}$, Clément Prati ${ }^{1,2}$ Daniel Wendling ${ }^{1} .{ }^{1}$ CHRU Besancon, Rheumatology, Besançon, France; ${ }^{2}$ Université de Bourgogne - Franche Comté, EA 4267 PEPITE, Besançon, France

Background: Spondyloarthrits is characterized by inflammatory back pain Anterior chest wall pain is common and a previous study reported a prevalence à $37 \%$ of ultrasonographic lesions of this anatomical region [1].

Objectives: The objective of this study is to evaluate, in patient with Spondyloarthritis, the prevalence of ACW ultrasonographic lesions after a follow up of 5 years and to identify factors associated with the development of new lesions.

Methods: This a monocentric and prospective study including patients with Spondyloarthritis meeting the ASAS 2009 criteria. Patients were followed during five years. ultrasound B mode and power Doppler examination of the two sternoclavicular joint and the manubrio-sternal joint were performed by the same two examinators at baseline and five years later. The presence of erosion, synovitis, ankylosis, power Doppler signal, joint effusion and bone margin narrowing were assessed. Clinical characteristics and disease activity were evaluated at 5 years. Results: In the 136 patients at baseline, 58 patients were evaluated 5 years later. The mean age was $48.2+/-11.9$ years old, with $86 \%$ male and $89 \%$ HLA B27. $60.3 \%$ of these patients had a history of pain of the ACW. The prevalence of ultrasonographic involvement of the ACW was $34 \%$ at baseline and $67.2 \%$ five years later. The most frequent lesions were ankylosis of the manubriosternal joint (38\%) and erosions of the sternoclavicular joint (29\%). At 5 years, patients with lesions of the ACW are significantly older $(51.4+/-11.5$ VS $41.5+/-9.98, \mathrm{p}<0,01)$. There were no differences concerning the presence of HLA B27 and the presence of a radiographic sacroilitis or syndesmophytes. Among these 58 patients, $31(53 \%)$ developed a new lesion of the ACW. There is a statistically significant association between a higher ASDAS CRP and new lesions of the ACW $(1,86+/-1,07$ VS $3,0+/-2,17 p<0,01)$ and with the level of CRP $(5,34+/-7,85$ VS $16,2+/-35, p=0,035)$. Baseline ASDAS CRP is not a predictor of new chest wall lesions prior to 5 years of age. Nevertheless, poor control of disease activity is associated with the development of new lesions. Patients with new lesions have an ASDAS CRP score that increase $(0,882+/-2,48)$ between 2013 and 2018, while patients with no new lesions have an ASDAS CRP score that decrease $(-0,641+/-1,50)$ between 2013 and 2018 .

Conclusion: The prevalence of ultrasonographic lesions of the ACW increased after 5 years of follow up. The development of new lesions is associated with a higher disease activity, a higher CRP and an increased disease activity over 5 years.

\section{REFERENCES:}

[1] ]Verhoeven $\mathrm{f}$. et al. Ultrasonographic evaluation of the anterior chest wall in spondyloarthritis: a prospective and controlled study.J Rheumatol. 2015;42:87-92 